\title{
Mortality and morbidity pattern in goats under organized farm conditions of Kerala
}

\author{
Deepak Chandran', P. M. Rojan² \\ Thirupathy Venkatachalapathy ${ }^{3}$ and A. S. Lejaniya ${ }^{4}$ \\ University Goat and Sheep Farm, Mannuthy, Thrissur \\ Kerala Veterinary and Animal Sciences University
}

Citation: Deepak, C., Rojan, P. M., Thirupathy, V.R. and Lejaniya. A. S. 2021. Mortality and Morbidity pattern in goats under organized farm conditions of Kerala. J. Vet. Anim. Sci. 52(2): 175-179. DOI: https://doi.org/10.51966/jvas.2021.52.2.175-179

Received: 11.12.2020

Accepted: 31.01 .2021

Published: 01.06 .2021

\begin{abstract}
A study was undertaken to find out the morbidity and mortality pattern in the goat population of Kerala. Factors such as cause, age, sex, breed, season and year were included in the study. Data were collected from 3925 goats maintained at The Goat and Sheep Farm, KVASU, Mannuthy for six years from 2011 to 2017 to assess the effect of different factors. Data pertaining to 2649 goats from 2013 to 2017 were analysed to find out the morbidity pattern among goats. The overall mortality rate was 11.76 per cent. Among the various causes of mortality, the results of this study indicated that mortality due to enteritis was the highest $(40.60 \%)$ followed by that due to pneumonia (22.88\%) and acidosis (10.40\%). The effect of age, season, sex and year on goat mortality were significant $(p<0.05)$. Mortality was the highest in the age group of $0 .-3$ months followed by 3-6 months. The incidence of mortality rates were 4.67, 5.09 5.27 and 5.26 per cent in pre-monsoon, south-west monsoon, post-monsoon and winter respectively. Mortality was more in females $(64.11 \%)$ than males. Mortality was highest in cross bred goats followed by Malabari and Attappady black, but not significant. The proportional morbidity due to foot rot was the highest (35.28\%) followed by enteritis (16.03\%) and orf (7.65\%). Highest morbidity was observed during south west monsoon (45.55\%) followed by post monsoon (21.98\%) and pre monsoon (18.14\%). The results of this study suggest that proper management during first three months of age especially during south west monsoon was critical to minimise mortality among goats.
\end{abstract}

Key words: goat, morbidity, mortality

1. Assistant Professor, School of Agricultural Sciences, Amrita Vishwa Vidyapeetham University Email ID: drdeepakchandran24@gmail.com, Phone : 9400723398

2. Assistant Professor, Department of Genetics and Animal Breeding, College of Veterinary and Animal Sciences, Pookode

3. Professor and Head, University Goat and Sheep Farm, Mannuthy, Thrissur, Kerala Veterinary and Animal Sciences University

4. Veterinary Surgeon, Animal Husbandry Department, Government of Kerala

Copyright: ( ) 2021 Deepak Chandran et al. This is an open access article distributed under the terms of the Creative Commons Attribution 4.0 International License (http://creativecommons.org/licenses/by/4.0/) which permits unrestricted use, distribution, and reproduction in any medium, provided the original author and source are credited. 


\section{Introduction}

Goat is considered as a versatile animal, adapted to different agroclimatic conditions of the world with more than 95 percent of the goat population found in developing countries. India possesses 135.17 million goats which makes up around 26.4 percent of total livestock in the country, ranking second in goat population of the world (Livestock census-19 $9^{\text {th }}$, 2012). Goat contributes 3.7 percent (4.8 MT) of the India's total milk (127.90 MT) production (Basic Animal Husbandry Statistics, 2013). Goat meat is chosen irrespective of religion or culture; therefore, goat meat has great demand in India. The productivity of goats under traditional production systems is very less.

Commercial goat production is gaining momentum, on account of good economic prospects of this system under the intensive and semi-intensive system. Goats contribute more than 52 percent of households' total income towards nutrition and food security of the rural families involved in this vocation (Kumar, 2007). Under organized farm conditions, mortality due to one reason or another is a matter of concern for producers, because it is directly linked with economic loss. Kumar et al. (2003) reported that estimated losses due to diseases in goats were 23.22 percent of net returns and 5.21 percent of gross returns. Economic losses due to mortality caused by various diseases in goats have been a major constraint in native flocks. The risk of disease further increases when goats are maintained in large flocks under the intensive system. To make goat farming profitable, in addition to good managemental practices, measures to ensure that the herd is made free from diseases and other health o problems should also be ensured (Singh and Kumar, 2007).

Morbidity and mortality greatly affect economic returns from goat husbandry. Knowledge of disease pattern in different age groups, breeds, sex, year and seasons will be of immense help in health management to reduce mortality. Several studies have shown that on an average 20 percent of kids and 10 percent of adult goats die each year (Ershaduzzaman et al., 2007). Therefore, the mortality and morbidity pattern of the farm should be known in order to plan proper management and prevention strategies. Keeping these aspects in view, the present study was undertaken to ascertain factors affecting morbidity and mortality pattern in goats under organized farm conditions of Kerala, India.

\section{Materials and Methods}

Data in this study were obtained from University Goat and Sheep Farm, Mannuthy. Mortality data of 3925 goats for the time period 2011 to 2017 and morbidity data of 2649 goats for the time period 2013 to 2017 . The data were classified as per their respective season, year, breed, sex and age of the animal. The calendar year was divided into 3 seasons: March-May (Pre-monsoon), June-September (South-West monsoon), October-November (Post monsoon) and December-February (Winter). The time period from birth to death was divided into three age groups kids (0-3 months), young goats (3-6 months) and adults (> 6 months). The breeds analysed include Attappady black, Malabari and cross-bred goats. The collected data were compiled and analyzed to study the incidence and effects of diseases in goats.

Proportional morbidity and mortality rates:

Among various diseases the proportional morbidity/ mortality (PMR) due to each disease was calculated by the formula:

$$
\begin{aligned}
& \text { Morbiditity Rate }(P)=\frac{\text { Number of animals affected by the specific disease }}{\text { Total number of animals affected by all the diseases }} \times 100 \\
& \text { Morbidity Rate }(P)=\frac{\text { Number of animals died due to the specific disease }}{\text { Total number of animals died due to all the diseases }} \times 100
\end{aligned}
$$

\section{Statistical analysis}

The percent mortality rate, morbidity rate and their distribution pattern for different years and season were calculated. The effect of different factors such as year, season, age, sex and causes of death with both mortality rate and morbidity rate were analyzed by one way ANOVA using SPSS software version 20.0 using the following model (Snedecor and Cochran, 1994). 
$y_{i j k l m}=\mu+A_{i}+B_{j}+C_{k}+D_{l}+E_{m}+e_{i j k l m}$

Where $y_{i j k m}$ is the observed value of $\mathrm{i}^{\text {th }}$ treatment,

$\mu=$ population mean effect,

$A_{i}=$ effect of year,

$B_{j}=$ effect of season,

$C_{k}=$ effect of sex,

$D_{l}=$ effect of breed,

$E_{m}=$ effect of age, and

$e_{i j k l m}$ is the error term

\section{Results and Discussion}

The overall mortality rate was 11.76 percent, which varied from 4.28 percent (2013) to 20.82 percent (2016). The lower mortality rate in the particular years could be due to small number of kids born, more kids being born in the favourable kidding season and better management conditions when compared to the years having higher mortality (Barbind and Dandewar, 2004 and Ramachandran et al., 2006).

The major diseases instrumental in causing deaths in the present study were diarrhoea, pneumonia, acidosis and enterotoxaemia. The mortality due to enteritis $(40.60 \%)$ was the highest, followed by that due to pneumonia $(22.88 \%)$ and acidosis $(10.40 \%)$. The overall morbidity rate was 19.95 percent. Foot rot remained the most frequently contracted disease especially during the post monsoon period, followed by digestive and respiratory diseases and further by some specific diseases like orf, mastitis and coccidiosis.

Table 1: Percent mortality and morbidity in different age groups of goats

\begin{tabular}{|c|c|c|c|c|c|c|c|}
\hline Year & $<\mathbf{3}$ Months & $\mathbf{3 - 6}$ Months & $\mathbf{>}$ ( Months & $\begin{array}{c}\text { Total } \\
\text { Death }\end{array}$ & Stock & Mortality \% & Morbidity \% \\
\hline 2011 & 26 & 20 & 3 & 49 & 628 & 7.80 & (not known) \\
\hline 2012 & 48 & 37 & 6 & 91 & 648 & 14.04 & (not known) \\
\hline 2013 & 15 & 12 & 2 & 29 & 676 & 4.28 & 7.47 \\
\hline 2014 & 45 & 34 & 5 & 84 & 652 & 12.88 & 7.74 \\
\hline 2015 & 58 & 45 & 6 & 109 & 615 & 17.72 & 28.10 \\
\hline 2016 & 46 & 35 & 5 & 86 & 413 & 20.82 & 45.99 \\
\hline 2017 & 7 & 6 & 1 & 14 & 293 & 4.78 & 10.70 \\
\hline Total & $\mathbf{2 4 5}$ & $\mathbf{1 8 9}$ & $\mathbf{2 8}$ & $\mathbf{4 6 2}$ & $\mathbf{3 9 2 5}$ & $\mathbf{1 1 . 7 6}$ & $\mathbf{1 9 . 9 5}$ \\
\hline
\end{tabular}

Effect of season on mortality and
morbidity

Different seasons of the year had a profound and significant effect $(p<0.05)$ on both mortality and morbidity. Season wise mortality within the year indicated that the highest mortality was during the South West monsoon $(39.28 \%)$ followed by pre monsoon (32.48 \%) and post monsoon (18.47\%) season. Highest morbidity was during South West monsoon $(45.54 \%)$ followed by the pre monsoon (21.98 $\%$ ) and post monsoon (18.1 $4 \%$ ) seasons. Such fluctuation in survivability could be attributed to variations in climatic conditions and high incidence of some specific diseases in a particular season (Awemu et al., 1999 and Dohare et al., 2013).

\section{Effect of Year on mortality and morbidity}

The variable year had a significant effect $(p<0.05)$ on both mortality and morbidity. Relatively higher instances of death and disease incidence occurred during 2015 and 2016.

\section{Effect of breed on mortality and morbidity}

Breed also had a significant effect on mortality and morbidity. Disease incidence and deaths were relatively higher in Malabari goats when compared to other breeds.

\section{Effect of Age on mortality and morbidity}

Age had a significant effect on both mortality and morbidity. Deaths and risk of contraction of disease is always higher in kids and young stock when compared with the adult stock (Sabapara and Deshpande, 2010). 
Table 2: Percent mortality and morbidity in different season

\begin{tabular}{|l|c|c|c|c|}
\hline \multicolumn{1}{|c|}{ Season } & $\begin{array}{c}\text { Number of } \\
\text { deaths }\end{array}$ & $\begin{array}{c}\text { Number of disease } \\
\text { incidence }\end{array}$ & Moratlity \% & Morbidity \% \\
\hline Pre monsoon & 153 & 405 & 32.48 & 18.14 \\
\hline South West Monsoon & 185 & 1017 & 39.28 & 45.54 \\
\hline Post Monsoon & 87 & 491 & 18.47 & 21.98 \\
\hline Winter & 46 & 320 & 9.77 & 14.34 \\
\hline Total & 471 & 2233 & 100 & 100 \\
\hline
\end{tabular}

Table 3: Percent mortality and morbidity in different years

\begin{tabular}{|c|c|c|c|c|c|}
\hline Year & $\begin{array}{c}\text { Number of } \\
\text { deaths }\end{array}$ & $\begin{array}{c}\text { Number of disease } \\
\text { incidence }\end{array}$ & Mortality \% & $\begin{array}{c}\text { Average number of } \\
\text { deaths }\end{array}$ & $\begin{array}{c}\text { Morbidity } \\
\%\end{array}$ \\
\hline 2011 & 48 & (not taken) & $7.64 \%$ & $10.20 \%$ & (not known) \\
\hline 2012 & 90 & (not taken) & $14.33 \%$ & $19.10 \%$ & (not known) \\
\hline 2013 & 37 & 167 & $5.89 \%$ & $7.85 \%$ & 7.47 \\
\hline 2014 & 84 & 173 & $13.37 \%$ & $17.84 \%$ & 7.74 \\
\hline 2015 & 114 & 627 & $18.15 \%$ & $24.20 \%$ & 28.10 \\
\hline 2016 & 84 & 1027 & $13.37 \%$ & $17.84 \%$ & 45.99 \\
\hline 2017 & 14 & 239 & $2.23 \%$ & $2.97 \%$ & 10.70 \\
\hline Total & 471 & $\mathbf{2 2 3 3}$ & & & \\
\hline
\end{tabular}

Table 4: Percent mortality and morbidity in different breeds

\begin{tabular}{|c|c|c|c|c|}
\hline Breed & Number of deaths & Number of cases & Mortality \% & Morbidity \% \\
\hline Attappadi black & 128 & 564 & 27.18 & 25.26 \\
\hline Malabari & 169 & 1277 & 35.88 & 57.19 \\
\hline Cross bred & 174 & 392 & 36.94 & 17.55 \\
\hline Total & $\mathbf{4 7 1}$ & $\mathbf{2 2 3 3}$ & & \\
\hline
\end{tabular}

Table 5: Percent mortality and morbidity in different age groups

\begin{tabular}{|c|c|c|c|c|}
\hline Age & Number of deaths & $\begin{array}{c}\text { Number of disease } \\
\text { incidence }\end{array}$ & Mortality \% & Morbidity \% \\
\hline $0-3$ months & 204 & 347 & 43.33 & 15.54 \\
\hline $3-6$ months & 230 & 958 & 48.83 & 42.90 \\
\hline Above 6 months & 37 & 928 & 7.84 & 41.56 \\
\hline Total & $\mathbf{4 7 1}$ & $\mathbf{2 2 3 3}$ & & \\
\hline
\end{tabular}

Table 6: Percent mortality and morbidity in males and females

\begin{tabular}{|c|c|c|c|c|}
\hline Sex & Number of deaths & Number of disease incidence & Mortality \% & Morbidity \% \\
\hline Male & 169 & 99 & 35.89 & 4.44 \\
\hline Female & 302 & 2134 & 64.11 & 95.56 \\
\hline Total & $\mathbf{4 7 1}$ & $\mathbf{2 2 3 3}$ & & \\
\hline
\end{tabular}

Effect of sex on mortality and morbidity

Sex had a significant effect on both mortality and morbidity. Higher mortality and morbidity were observed in female animals. The low mortality in male animals could be due to their lesser presence on the farm at a given time as there was a practice of disposing male animals from the farm immediately after weaning (Singh et al., 2004 and Singh et al., 2008).

\section{Conclusion}

This study confirms that overall mortality rate averaged 11.76 per cent under 
semi-intensive farm conditions. It was generally higher during south-west monsoon followed by pre monsoon and post monsoon seasons. Season-wise mortality followed a similar trend for all age groups. Mortality was higher in kids particularly those under 1 month of age than in young stock and adults. The disease which singly contributed major share to overall mortality included digestive diseases followed by respiratory diseases and parasitic diseases. It was revealed that diarrhoea and pneumonia were the major causes of morbidity, warranting improved hygiene and good management practices on goat farms should be taken to reduce the occurrence of diseases. Morbidity and mortality were significantly associated with age suggesting that more care and attention needed to be paid to kids of less than 3 months of age irrespective of the season. Mortality due to various diseases in kids and adults could be minimized by identifying the cause and giving proper treatment.

\section{References}

Awemu E.M., Nwakalor L.N. and Abubakar B.Y. 1999. Environmental influence on Weaning mortality and reproductive performance on Red Sokoto does. Small Rumin. Res. 34: 155-160.

Barbind R.P. and Dandewar B.I. 2004. Preweaning mortality pattern in Osmanabadi crossbred goats. Indian J. Anim. Res. 38: 75-76.

Basic Animal Husbandry Statistics, (BAHS) Series-14. [Dated 23 September] 2013. Government of India, Ministry of Agriculture, Department of Animal Husbandry Dairying and Fisheries.

Dohare A.K., Singh B., Bangar Y., Prasad S., Kumar D. and Shakya G. 2013. Influence of age, sex and season on morbidity and mortality pattern in goats under village conditions of Madhya Pradesh. Vet. World. 6(6): 329-331.

Ershaduzzaman M., Rahman M.M., Roy B.K. and Chowdhury S.A. 2007. Studies on the diseases and mortality pattern of goats under farm conditions and some factors affecting mortality and survival rates in black bengal kids. Bangladesh J. Vet. Med. 5(1\&2): 71-76.

Kumar S. Commercial goat farming in India. 2007. An emerging agri-business opportunity. Agric. Econ. Res. Rev. 22: 503-520.

Kumar S., Vihan V.S. and Deoghare P.R. 2003. Economic implications of diseases in goats in India with reference to implementation of a health plan calendar. Small Rumin. Res. 47: 159164.

Livestock Census-19 ${ }^{\text {th }}$. Department of Animal Husbandry Dairying and Fisheries, Ministry of Agriculture, Government of India. 2012. [Accessed on 10-12-2014]. Available from: http://www.dahd.nic.in/ dahd/default.aspx.

Ramachandran N., Prasad S. and Raju S. 2006. Mortality pattern in crossbred dairy goats in semiarid India. Indian J. Anim. Sci. 76(10): 843-846.

Sabapara G. P. and Deshpande S. B. 2010. Mortality pattern in Surti goats under field condition. Vet. World. 3(4): 165-166.

Singh M.K., Rap B. and Sharma N. 2008. Factors affecting survivability of Jamunapari kids under semi-intensive management system. Indian J. Anim. Sci. 78(2):178181.

Singh N.P. and Kumar S. 2007. Jabalpur 9-11 March: Proceedings of 4th National Extension Congress J.N.K.V.V. An alternative approach to research for harnessing production potential of goats.

Singh R.B., Tomar S.S. and Singh C. 2004. Age specific mortality of females beetal and crossbreed goats. Indian J. Small Rumin. 10: 101-103.

Snedecor G.W. and Cochran W.G. 1994. Statistical Methods. 9th ed. Ames: lowa State University Press. 